\title{
Impact of Strontium on the Hardness and Impact Test of Eutectic Al-Si+1.0\% Manganese Alloy
}

\section{Okwonna Chukwuebuka Onochie}

Department of Mechanical Engineering, Micheal Okpara University of Agriculture, Umudike, Nigeria

\section{Email address:}

Okwonnac@yahoo.com

\section{To cite this article:}

Okwonna Chukwuebuka Onochie. Impact of Strontium on the Hardness and Impact Test of Eutectic Al-Si+1.0\% Manganese Alloy. International Journal of Mechanical Engineering and Applications. Vol. 9, No. 4, 2021, pp. 72-74. doi: 10.11648/j.ijmea.20210904.12

Received: April 1, 2021; Accepted: May 20, 2021; Published: September 23, 2021

\begin{abstract}
This experimental research portrays the impact of strontium seen on hardness and impact strength of Al-1.0\%mn$12 \% \mathrm{Si}$ alloy. Strontium was added with respect to the amount of silicon present in the alloys $(12 \%$ of $\mathrm{Si} ; 0.02-0.03 \%$ of $\mathrm{Sr})$ and $1.0 \%$ manganese which serves as a modifying agent). Higher amount of aluminum and silicon were dissolved and cast as cylindrical ingots. Impact and Hardness test were tested using charpy impact testing machine and Rockwell hardness testing machine (ASTM E18-11) respectively. The addition of Sr appears to decline as soon as the addition exceeds the $0.026 \%$ level which shows negative effect to the mechanical properties because of the presence of some compounds like Al4SrSi2 and releases of brittle $\mathrm{Al} 3 \mathrm{SrSi} 3$ phase are bound to set and coarsening of the eutectic silicon can occur which will reduce the properties of the alloy causing them to revert to values more typical of unmodified material. The results showed that when strontium was used as a modifier to modify eutectic $\mathrm{Al}-\mathrm{Si}$ alloy modifies the $\mathrm{Al}-\mathrm{Si}$, that the morphology of the alloy changed that lead to positive enhancement/increment in mechanical properties of the alloy.
\end{abstract}

Keywords: Strontium, Aluminum Alloy, Eutectic Alloy, Impact Strength, Hardness

\section{Introduction}

Aluminum becomes the common structural material because of following properties: less weight, less energy needed to fabricate and machine, not easily affected by atmospheric corrosion, good thermal as well as electrical conductivities, high metallic soft glow and its non to conduct and non-shine in nature [2]. Al-Si alloy belongs to aluminum die-casting alloys because of its applications especially in the automotive industry, as well as, the aerospace industry. Aluminum which is needed much in the automobile industry because the propulsive force of materials required is proportional to the design of lighter components which will help reduce the rate of intake of fuel but will not affect the quality and environment [3]. Aluminum alloys are becoming important in the industry because of the way it combines with the properties of base alloy. These properties include high strength, high wear resistance, high rate of stiffness, high temperature strength, efficient of the thermal expansion that is controlled and damping capacity that is improved [7]. Aluminum-Silicon alloys plays vital role in engineering industries because the ratio of the strength to weight is high, they equally posses high wear resistance, low density and the level of coefficient of thermal expansion is low. Complex shapes can formed through casting with Al-Si alloys but the brittle needle-like shape formed because of the presence of silicon particles reduces the impact strength in the cast structures. One of the main reasons for using these alloys to make high-quality castings is eutectic modification, which was accidentally discovered by AladarPacz in the 1920's while using an alkali-fluoride treatment in Al-Si melts. This treatment results in a considerable improvement in mechanical properties, especially elongation by altering the form of the silicon which is a major constituent of these alloys and plays a significant role in determining the mechanical properties of the alloys.

The use of aluminum cast alloys is still limited when compared with wrought alloys, not withstanding that casting would save more money during production [9]. Apart from the emerging money saving processing techniques that joins quality and ease of operations, researchers are, at the same time changing to aluminum-silicon mix and isotropic 
properties, especially in connection to applications that does not need high loading or high heat conditions, for example automobile components [4]. Silicon that appears in brittle needle-like particles and that causes reduction in impact strength especially cast structures. The finger-like structure formed reduces the stress raisers that bring cracks which will reduce the mechanical strength of the alloy [8]. Also, there are plenty impurities found in commercial aluminum which can only be expunged at great cost. Iron is found to be the most important impurity tending to reduce harm in cast aluminum and its alloy reduces the mechanical properties like fracture toughness. The best method improving the stability of aluminum-silicon alloy usage in the industry is to improve the mechanical properties by making sure that $\mathrm{Al}-\mathrm{Si}$ is structurally sound and dimensionally accurate during castings and when the parts are been fabricated at reduced price. The best way to improve the mechanical properties of $\mathrm{Al}-\mathrm{Si}$ is by first understanding the relationship that exists between the structure, the property and application of the aluminum-silicon alloy additives. Good in-depth understanding of the coexistence between the microstructure and the properties in cast $\mathrm{Al}$ alloys in conjunction with improved foundry practice will allow greater application of the castings in low mass structures. The reasons why modifiers are added to $\mathrm{Al}-\mathrm{Si}$ alloys are to improve the strength of the alloy, the mechanical properties of the alloy and equally reduce porosity and shrinkage as they change and improve the eutectic structure [1]. Modifier additions during casting of Al-Si alloys improves the mechanical properties especially the ductility of the cast Al-Si alloy [5, $13,14]$. The improvement in mechanical properties of the cast Al-Si alloy is as a result of the change in the form, shape, structure and size of the eutectic silicon phase particles [15]. However when eutectic silicon particles changes from acicular to fiber that its form, shape and size of dendritic $\alpha$ Al phase are changed as well.

\section{Materials and Method}

The materials used for alloy preparation, casting of test bars and testing are: aluminium, silicon, manganese, strontium, Weighing machine, Mild steel pot (fabricated) and laboratory size tungsten-arc electric furnace for melting. Four different make ups of alloys were produced with number of strontium ranging from 0-02-0.03 wt\%. Before casting, sample A which was the control sample was analyzed chemically to check its makeup and after the casting the samples were also analyzed to check the effect strontium had on the alloys as seen in Table 1. Compositions were melted in a crucible furnace separately in alumina crucible and after crucible were removed from the furnace then modifiers addition followed. The crucibles were taken back to the furnace and furnace temperature raised from $750 \mathrm{oC}$ to $800 \mathrm{oC}$ because the modifiers suppose not to melt instead form intermetallic phase in the Al-Si alloy. The hardness test was done in accordance with $[10,11]$. The techniques to follow for the experiments are: i. Pattern making/Moulding

ii. Casting/Preparation of samples

iii. Machining

iv. Characterization and testing

Table 1. Chemical analysis of the alloys.

\begin{tabular}{llllll}
\hline Samples & $\mathbf{\% ~ S i}$ & $\mathbf{\% ~ M n}$ & $\mathbf{\% ~ S r}$ & $\mathbf{\% ~ F e}$ & $\mathbf{\% ~ A l}$ \\
\hline Sample A & 11.54 & 1.0 & 0.02 & 0.78 & Bal \\
Sample B & 11.55 & 0.92 & 0.024 & 0.73 & Bal \\
Sample C & 11.55 & 1.01 & 0.026 & 0.60 & Bal \\
Samples D & 11.58 & 1.00 & 0.028 & 0.55 & Bal \\
Sample E & 11.56 & 1.00 & 0.03 & 0.48 & bal \\
\hline
\end{tabular}

\section{Results and Discussions}

The table and graph below shows the result of the impact of manganese and strontium additions on the hardness and impact strength of $\mathrm{Al}-12 \% \mathrm{Si}$ alloy. Table 2 and Figures 1 and 2 showed the result of the hardness and impact strength carried out on the modified Al-Si eutectic alloys.

Table 2. Result of impact and hardness test of modified Al-Si eutectic alloy.

\begin{tabular}{lll}
\hline Sample & hardness & Impact strength \\
\hline Sample A & 53.5 & 2.3 \\
Sample B & 61.3 & 2.5 \\
Sample C & 59.6 & 2.9 \\
Sample D & 62.2 & 2.6 \\
Sample E & 60 & 3.0 \\
\hline
\end{tabular}

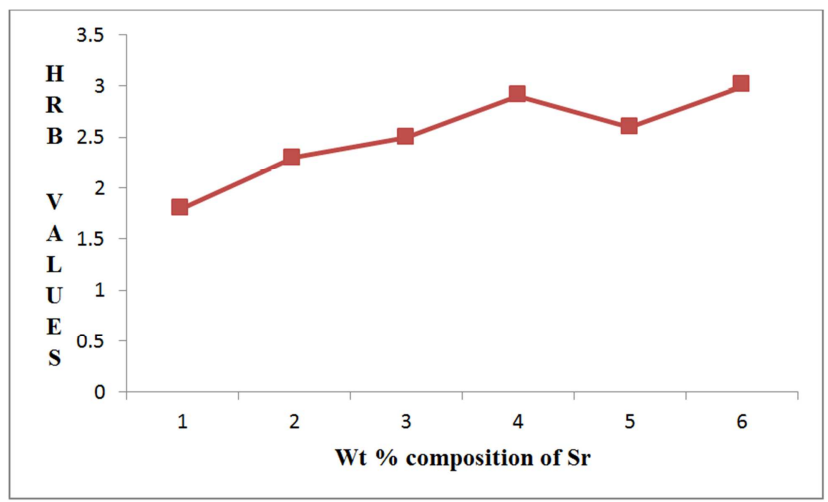

Figure 1. Impact of Sr on the hardness of Al-12\% Si alloy.

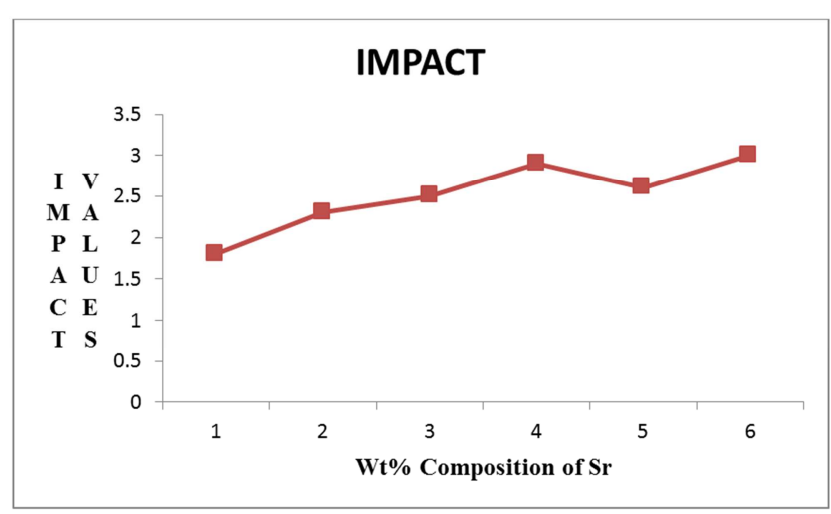

Figure 2. Impact of $\mathrm{Sr}$ on the impact strength of $\mathrm{Al}-12 \% \mathrm{Si}+1 \% \mathrm{Mn}$ alloy.

The addition of $\mathrm{Sr}$ increases resilience and durability of the 
material up to the point $0.028 \mathrm{wt} \%$ when addition of $\mathrm{Sr}$ tends to decrease the material strength in term of impact load. Figure 2 portrays the impact of addition of $\mathrm{Sr}$ on the impact strength. When $\mathrm{Sr}$ was added, Al-12\%Si alloy increases its fracture energy 2.3 Joule to 2.6 Joule and 3.0 joule. On the other hand, the addition of $0.028 \mathrm{Sr}$ tends to decrease the fracture energy of $\mathrm{Al}-12 \% \mathrm{Si}$ alloy to 2.1 Joule not withstanding that it equally increased the fracture energy when there was no addition of strontium to the alloy. However, the effect appears to decline as soon as the addition exceeds the $0.026 \%$ level which shows negative effect to the mechanical properties because of the presence of some compounds like $\mathrm{Al} 4 \mathrm{SrSi} 2$ and releases of brittle $\mathrm{Al} 3 \mathrm{SrSi} 3$ phase are bound to set and coarsening of the eutectic silicon can occur which will reduce the properties of the alloy causing them to revert to values more typical of unmodified material [6].

\section{Conclusion}

The following can be drawn from the research such as when low level of strontium was added the amount of porosity in the alloy modified the eutectic Si morphology from acicular to fine fibrous form with increase in hardness and impact strength. Fine dispersion of silicon particles seen in the alloy changed the structure of the alloy thereby improving the final mechanical properties of Al-Si alloy. Hence it can be seen that addition of strontium produced better and good mechanical properties because of the change in the shape of silicon.

\section{References}

[1] Atasoy, I. Ö. A. (1984a): "Determination of Strontium in Aluminum-Silicon Eutectic Alloys with the Atomic Absorption Spectrophotometer"; ALUMINIUM English Edition, Vol. 60, No. 1 (1984), pp E 12-13.

[2] Daintith, J. [ed.] (2000):“'Oxford Dictionary of Chemistry, Fourth Edition". New York: Oxford University Press, Inc.

[3] Mbuya, T. O, (2003) 'Influence of iron on castability and properties of aluminium silicon alloys; literature review' international journal of cast metals research, 16 (5), pp, 451465 .
[4] Chawla, K. K, Liaw, P. K and Fishman, S. G, (1996)."HighPerformance Composites: Commonalty of Phenomena" (Conference Review), JOM, 48 (2), pp. 43-44.

[5] Liao H, Sun Y, Sun G (2002), Correlation between mechanical properties and amount of dendritic $\alpha$-Al phase in as-cast neareutectic Al-11.6\% Si alloys modified with strontium. Journal of Materials Processing Technology A335.

[6] Okwonna, C. O (2013). The Influence of additives on Al-Si eutectic alloy. M. Sc project, University of portharcourt, Nigeria.

[7] Szymczak, Cz. k, Kujawa, M. (2017). Local bucling of thinwalled channel member flange made of aluminum alloy. AIP Conference Proceedings 1822, 020014; doi: 10.1063/1.4977688.

[8] Zheng. Y. O, Zhang, Z. (2016). The performance and fire resistance of aluminium alloy I-beam, fire and Materials.

[9] Summers, P. Y. T., Chen, Y., Rippe, ch. M., Allen, B., Mouritz, A. P., Case, S. W., Latimer, B. Y (2015). Overview of aluminium alloy mechanical properities.

[10] ASTM E 18-08b- Standard Test Methods for Rockwell Hardness of Metallic Materials

[11] Andrzej Ambroziak (2018). Application and mechanical properties of aluminium alloys. Gdansk University of Technology, faculty of civil and environmental engineering Poland. Pp 525-528.

[12] Alaco metals (2019) Aalco Metals Ltd, Parkway House, Unit 6 Parkway Industrial Estate, Wednesbury WS10 7WP

[13] Rosmanamuhanandi R, Sulaimans, Azmah M. I. S, Talari M. $\mathrm{K}$ (2018). Characterization of Al-Si cast alloy refined with titanium diboride and scandium $(\mathrm{Sc})$. Journal of mechanical engineering 5 (1), 62-70.

[14] Ibrahim R. E, Sabrina M, smamuhamadni R, Yahaya m, Suliaimann S, Ismali M. I. S (2018). Corrosion behavior of Al-Si cast alloy reinforced with titaniumdiboride (TiB2) and scandium. Journal of engineering and science research (2) 1-8.

[15] Basir N. N. A, Mustafa N. H, Ibrahim R. E, Rosmamuhamadani R (2019). Mecahnical Characterization of Al-Si-TiB2 reinforced by scandium $(\mathrm{Sc})$ and Strontium $(\mathrm{Sr})$. International Journal of engineering and technology. 7 (4.14): 392. 